\title{
AN OVERVIEW OF ENHANCING DROUGHT TOLERANCE IN COTTON THROUGH MANIPULATING STRESS RESISTANCE GENES
}

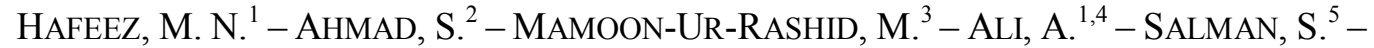 \\ BAKHSH, A. ${ }^{6}$ - MAHPARA, S. ${ }^{6}-$ KAMARAN, $^{6}{ }^{6}-$ RAMZAN, I. $^{5}-$ WASEEM, M. ${ }^{7}-$ Ali, Q. ${ }^{1,8^{*}}$ \\ RASHID, B. ${ }^{1}$ \\ ${ }^{I}$ Centre of Excellence in Molecular Biology, University of the Punjab Lahore, Lahore, Pakistan \\ ${ }^{2}$ Institute of Agricultural Sciences, University of the Punjab Lahore, Lahore, Pakistan \\ ${ }^{3}$ Department of Entomology, Faculty of Agriculture, Gomal University, Dera Ismail Khan, \\ Pakistan \\ ${ }^{4}$ 1-FB. Genetics, Four Brothers Group, Lahore- Pakistan \\ ${ }^{5}$ Department of Plant Breeding and Genetics, Gomal University, Dera Ismail Khan, Pakistan \\ ${ }^{6}$ Department of Plant Breeding and Genetics, Ghazi University, Dera Ghazi Khan, Pakistan \\ ${ }^{7}$ Department of Agronomy, Faculty Agriculture, Lasbela University of Agriculture, Water and \\ Marine Science, Uthal, Lasbela, Pakistan \\ ${ }^{8}$ Institute of Molecular Biology and Biotechnology, University of Lahore, Lahore, Pakistan \\ *Corresponding author \\ e-mail:saim1692@gmail.com \\ (Received 20 $0^{\text {th }}$ Feb 2019; accepted $8^{\text {th }}$ Apr 2019)
}

\begin{abstract}
Drought stress affects the normal growth of plant by influencing Physiological, morphological molecular and biochemical traits at cellular level. It is a polygenic trait, controlled by multiple genes, which makes its manipulation difficult by genetic engineering. It seems drought could be major threat in future to high yield of cotton in Pakistan as well around the globe because it is spontaneous and cannot be controlled with manuring and skilled agricultural practices. Gene manipulation could be a solution of this threat by producing transgenic cotton plants. As it is polygenic trait, so, understanding about cellular mechanism of drought tolerance is crucial to impart tolerance by controlling gene expression under stressed conditions. Universal Stress Proteins (USP) genes have already been identified in drought stressed leaves of Gossypium arboreum which make this variety of cotton a rich source of stress tolerance genes. USP genes could be manipulated for drought tolerant transgenic cotton with high yielding as well and it is most important family of proteins in this regard. This family encompasses a conserved group of proteins that has been reported in different organisms which are activating under various abiotic stress conditions. USP is also a regulatory protein; its activity can be increased by manipulating its interactions. Keywords: Gossypium arboreum, polygenic traits, drought stress, universal stress proteins, transgenic
\end{abstract}

\section{Introduction}

Unfavorable environmental conditions usually inhibit the normal plant growth. There are several abiotic factors, which interrupt the bumper growth of crops, among them drought is worth to be mentioned (Farooq et al., 2009). Drought means loss of water either at elevated or normal temperature. It triggers biochemical and physiological modifications at cellular level, among them loss of turgor pressure, changes in 
membrane fluidity, membrane composition, solute concentration, protein-lipid and protein-protein interactions are need to be studied. Plants respond to drought stress at physiological level as well as at molecular level. They activate diverse set of metabolic activities to defend themselves against drought stress and initiate their struggle to be survived at the onset of this extreme unfavorable condition (Fahramand et al., 2014). At genetic level, multiple genes are involved, which are responsible to initiate the defense system of plants. Hence, involvement of multiple genes makes it complex to control the drought resistivity of plants by using genetic engineering. However, different studies like transcriptomics, proteomics and expression of genes have identified the activation and regulation of several stress-related genes at cellular level. It has been observed that expression level of different genes in plants is changed under the spell of drought stress (Ribas et al., 2006).

Plants' responses against stresses are mounted and co-ordinated by two types of signaling pathways namely ABA-independent and ABA-dependent pathways. The products of these genes are classified as regulatory and functional proteins which are responsible to activate stress related pathways (Shinozaki and Yamaguchi-Shinozaki, 2007). Functional and regulatory proteins include enzymes for biosynthesis of osmolyte, water channel proteins, LEA-proteins, chaperones, detoxicating enzymes, proteinases, transcription factors, phospholipases and protein kinases. These functional and regulatory proteins are playing their role to regulate signal transduction mechanism and stress related gene expression (Sivamani et al., 2000). The interaction studies of the genes responsible for plants' biological processes are important to comprehend the mechanism of abiotic stresses in plants. Plants express a multitude of proteins containing USP domains. An analysis of different plant taxa shows that a plant contains an average of 200 different USP domain containing proteins (Maqbool et al., 2009; Isokpehi et al., 2011). Two genes have been identified in cotton which encodes USP proteins named GUSP1 and GUSP2 (Maqbool et al., 2009; Fahramand et al., 2014). These genes are up-regulated during drought stress. Studies conducted on the role of USP in tomato shows that USP activates two gene clusters. One cluster produces LHCB (light harvesting chlorophyll $\mathrm{a}$ and $\mathrm{b}$ binding proteins) and reduction in aperture of stomata aperture while second cluster produces osmo-protective compounds, i.e. proline. Furthermore, USP is also shown to interact with annexin proteins but the details about how actually the USP performs its functions are still to be elucidated (Loukehaich et al., 2012; Fahramand et al., 2014).

It has been observed that plants respond increasing osmo-protectant production, detoxification of ROS, biosynthesis of chlorophyll, increasing water uptake and stabilizing its proteins (Hayano-Kanashiro et al., 2009), all these processes are triggered by several genes. It is obvious from the previous studies that manipulation of drought responsive genes and maintenance of cellular components has remained as major target of attempts to produce plants having enhanced drought tolerance. Cotton (Gossypium spp.), is genetically diverse plant, it has four domesticated species. G. arboreum has many remarkable benefits over $G$. hirsitum, it has considerable resistance against biotic and abiotic stresses especially drought stress which makes it priceless gene pool to improve future cotton cultivars (Mehetre et al., 2003; Huang and Liu, 2006; Liu et al., 2006). Several stress proteins and soluble sugars have been reported to act as protectants during cell dehydration in many plants (Kosmas et al., 2006; Padmalatha et al., 2012). The universal stress protein (USP) is one of the most important family of protein for this purpose. USP is a cytoplasmic protein present in bacteria; its expression 
is enhanced, when cellular viability is challenged by drought spell and other abiotic stresses (Sousa and McKay, 2001; Maqbool et al., 2009; Zahur et al., 2009). The USP super family encompasses a conserved and ancient group of proteins that are present in archaea, bacteria, fungi, plants and flies (Kvint et al., 2003). E. coli contains six USP proteins (USPa, USPb, USPc, USPd, USPe, USPf), which are sub divided into two subgroups on the basis of their sequence similarity (Gustavsson and Nyström, 2002). It has been reported the presence of USP-genes in different organisms, where they are playing role in response to heat shock, cold shock, DNA management, metabolic control (Persson et al., 2007; Isokpehi et al., 2011; He et al., 2012; Mbah et al., 2013). Furthermore, USP is a regulatory unit protein; its activity can be increased by manipulating its interactions.

This review will cover the role of drought tolerance related gene in plants and their effect on cellular mechanism in response to drought stress (Maqbool et al., 2009; Zahur et al., 2009). A comprehensive screening of Universal Stress Protein gene-2 will enhance our basic knowledge about key metabolic pathways relating to drought and open ways for future engineering of drought stress tolerance. The functional and cellular characterization of USP genes would be investigated to ascertain its potential role in drought stress tolerance mechanism in plants especially in cotton. Understanding the mechanism of interaction of universal stress protein genes and its role in drought tolerance will enable us to breed economically important cotton varieties which are adapted to drought stress. The review will cover the major metabolic pathways in connection with drought tolerance, which will be helpful in providing direction for future metabolic engineering for drought-stress tolerance.

\section{What is abiotic stress?}

Negative influence of non living things of environment on living things in an ecosystem is called abiotic stress (Degenkolbe et al., 2009; Ali et al., 2013, 2017). The common stressors are easiest to identify, but some other are less recognizable stress factors which are affecting environment constantly (Kogan et al., 2013). Extreme temperature, drought, salinity, wildfire and sporadic floods are well known abiotic stresses in our ecosystem for plants. Hence, Scarcity of water resources, environmental pollution, salinity, intensified erosional problems are marked in the beginning of $21 \mathrm{st}$ century. All these offer abiotic stress to the plant growth, which is the limiting factor in crop yield around the world (Ali et al., 2014, 2016; Wang et al., 2003). Roots are first line of defense against any type of abiotic stress in plants, if soil is healthy, porous, well aerated and contain all essential nutrients then survival rate of plant is automatically increased. Furthermore, abiotic stress not only limits the crop productivity, (Jaleel et al., 2009) but also distribution of plants. Drought stress is major threat among abiotic stresses, which has drastic affects on yield and growth of plants. Drought is a metrological phenomenon which can be defined as a depletion of moisture to the economic injury level, because of prolong period of meager rain fall (Kramer, 1979).

\section{Effects of extreme water deficiency on plant growth}

Water deficiency results in loss of turgor pressure and osmotic stress in plants (Mansoor et al., 2003). The osmotic stress results in reduction of plant height, decrease in root length, yellowing of leaves because of reduction in chlorophyll content and 
overall growth rate of plant is reduced. Deficiency in nutrient distribution is another negative effect of drought stress. Reduction in water uptake from the soil to roots also results in slow entry of essential minerals such as nitrate, phosphorus, calcium and potassium into plant and in turn growth rate is ultimately reduced (Zhu et al., 2000). Secondary effect of water deficiency is oxidative stress because of the accumulation of excessive ROS (Reactive Oxygen Species) like hydroxyl radicals, hydrogen peroxide and superoxide anions. Usually ROS are found to be involved in normal metabolic reactions of cells, however, when plants are growing under water deficient environment, the amount of ROS increases to protect the cells from oxidative injuries (Altaf-Khan et

al., 2002). The exogenious use of 2,2-diphenyl-1-picrylhydrazyl, 3,3'-diaminobenzidine

and methyl viologen in Arabdopsis thaliana indicaetd that there was an over accomulation of reactive oxygen species under drought and oxidative stress conditions (Nakabayashi et al., 2014). The dry2/seqe1-5 (Arabidopsis drought

hypersensitive/squalene epoxidase 1-5) mutant was found to produce antioxidants as far

as the RHD2 NADPH oxidase was de-localized under drought stress conditions and

caused the formation of reactive oxygen species (Pose et al., 2009). Similarly, water deficiency results in the reduction of root and shoot length and their fresh and dry biomass, therefore roots and shoots may become thinner or thicker (Ashraf and Foolad, 2007). Studies have been revealed that water deficiency is a chief limiting aspect at initial stages of plant growth. Both cell elongation and cell division are severely affected by the drought stress (Bhatt and Rao, 2005; Koroleva et al., 2005; Shao et al., 2008). Various physiological and biochemical processes like ion uptake, respiration, photosynthesis, nutrient metabolism and translocation are severely affected by the reduction in plant growth as a result of drought stress. Similarly studies of Farooq et al. (2009) observed changes in chlorophyll a and b because of drought stress. All cash crops are affected by drought stress among them rice as a submerged crop is more susceptible to the drought stress (Jaleel et al., 2009). Another effect of water deficiency is reduction in the stem length (Specht et al., 2001). Similarly, 25\% reduction in plant height was observed in water stresses citrus seedlings (Wu et al., 2008). Significant reduction in the stem length of potato plant was also reported under drought stress (Heuer and Nadler, 1998). The height of other plants like, Petrosolinum crispum (Jaleel et al., 2007), Abelmoschus esculentus (Manivannan et al., 2007), and Vigna unguiculata (Petropoulos et al., 2008) were reported to be decreased. In short, effects of drought stress are characterized by diminished water potential, reduction of total water content, loss of turgor pressure, closing of stomata and reduction of cell division along with cell elongation. 


\section{Drought stress and cotton yield}

G. arboreum is diploid and possesses several desired characteristics (resistance to diseases and insect pests and tolerance to drought and salinity), while G. hirsutum are lacking these characters but it has high crop yield and fiber quality. G. arboreum provides space to cultivate it in semiarid and arid regions with minimum farming inputs. Besides this, it is also considered a vital gene pool source because of its distinctive qualities for improvement of other cotton cultivars via genetic engineering. Cost of irrigated cotton production is increasing continuously because of ground water supplies are decreasing in Pakistan; it forces to select drought tolerant cultivars as well as other agricultural commodities. Drought stress at very early stage affected the expansion of leaves in cotton and roots are less sensitive as compared to shoot growth (Malik and Srivastava, 1979; Quisenberry et al., 1985). It was found under drought stress leaf expansion was inhibited which results in decrease in utilization of energy and carbon finally result larger portion of assimilates are translocated to plant roots. Hence, characteristics plant roots can be used as important indicator to drought stress.

The consequence of drought stress on total yield of cotton depends upon severity and timing of drought spell. Krieg 1983) reported that crop yield was decreased under drought stress because of reduction in size and number of leaves and decrease in photosynthetic activity. It has also been observed that initiation of square to first flowering stage is the most susceptible development stage affected by water deficiency. The peak flowering stage was the more susceptible to drought stress which results in heavy losses to crop yield (Golldack et al., 2014). Cotton seeds yield was also decreased because of reduction in total number of bolls per plant under drought stress (Hamada, 2000) and also affected quality of lint in several ways, particularly fiber elongation; maturity and length was reported (Krieg, 1983).

\section{Sensitivity of cotton plant to drought stress}

Cotton plant is sensitive to drought stress during boll development and flowering stage (Turner, 1981; Isokpehi et al., 2011). The pollen tube formation in cotton is extremely sensitive to drought stress (Burke et al., 1985; Kawakami et al., 2010). There are several stages of flowering and boll formation in cotton because of perennial growth pattern so, the uncertainty has exists owing to conflicting reports about the sensitive stage of development to water deficiency (Gazanchian et al., 2007). The early flowering period in cotton, according to Umbeck (1987), is sensitive to drought stress while Vereyken et al. (2001) reported that peak flowering stages is more susceptible to drought stress which results in yield reduction of cotton. The production of fructans in phospholipids initiated under drought stress condition of plant cells (Vierling and Kimpel, 1992). Cotton bolls appear to be less sensitive to drought stress than the leaves since they are significantly resistant to water loss and are considered essentially nontranspiring (Quisenberry et al., 1985; Kawakami et al., 2010). A number of researchers however, have reported that limited supply of water during boll development can result in significantly lower yields (Koroleva et al., 2005). In support of these observations, (Quisenberry et al., 1985) it was observed that if drought stress occurs during the first fourteen days after anthesis (on set of flowering), young bolls generally abscise (fall off). Chaves et al., conducted growth chamber experiments where bract and capsule wall water potential of 5-, 20-, and 30-day old bolls was monitored along with leaf water potential under a moderate and a severe drought stress regime. They reported that 
mild drought stress had no effect on bract and capsule wall water potentials while leaf water potentials were significantly decreased (Chaves et al., 2009).

A similar pattern was observed under severe drought stress conditions with the exception of the dark respiration rates of the capsule wall that were significantly decreased under drought stress conditions. Bayely et al. (1992) reported that the inverted water potential gradient that was observed for the petals was also present in 20day after anthesis (on set of flowering) bolls. Water and osmotic potential of bracts and subtending to the bolls leaves compared to the bolls. This was attributed to the xylem connections of the fruits being immature and, hence non-functional, until three weeks post anthesis (on set of flowering), and it was concluded that since the water potential gradient is directed from the fruits to the leaves, the main entrance of water in cotton bolls is through the phloem (Vierling and Kimpel, 1992).

\section{Response of plants to drought stress}

\section{Morphological and physiological responses of plants}

It is reported that drought stress has drastic affects on plant growth while influencing various biochemical, morphological and physiological reactions, like photosynthesis, fluorescence of chlorophyll, stomatal conductance, ion uptake, respiration, translocation, nutrient metabolism, promoters of growth, carbohydrates, proline and malondialdehyde (MDA) contents and cellular integrity, (Jaleel et al., 2008; Shao et al., 2008; Farooq et al., 2009; Filippou et al., 2011). Susceptibility of crops to various environmental stresses frequently changes with growth stages of plant and requirements for best possible and development growth (Specht et al., 2001). In soybean shoot length and dry biomass was decreased under drought stress (Kawakami et al., 2010). Almost $25 \%$ decrease in the length of citrus seedlings observed (Wu et al., 2008) under drought stress. In potato, shoot length of plant was considerably affected because of drought stress (Heuer and Nadler, 1998), Vigna unguiculata (Manivannan et al., 2007) and Abelmoschus esculentus (Jaleel et al., 2008). Water uptake is also observed to be reduced under deficiency of which results in the decrease of water contents and elongation of cell is also inhibited because of decrease in turgor pressure.

\section{Leaf water potential}

Water potential is a potential energy of water per unit volume relative to pure water. It means to quantify the tendency of water to move from one place to another because of osmosis, gravity and mechanical pressure. Relative water potential is useful to understand the water movement within plants. The measurement of leaf water potential is a reliable indicator of drought stress (Farooq et al., 2009; Fahramand et al., 2014). Morgan (1984) revealed in a study that plants of drought tolerant cotton variety, $G$. arboreum have more number of cells and stomata per unit of leaf relative to the plants of drought intolerant cotton variety, G. hirsutum. Ackerson (1981) described while comparing 7 drought resistance and drought prone varieties of cotton that drought resistant varieties have minimum leaf water potential and have ability to maintain turgor at lower relative water potential than that of drought prone cotton plants. Because of turgor maintenance, photosynthesis continues in drought tolerant plants while drought intolerant plants are failed in doing so. Photosynthesis in drought tolerant varieties 
remain at maximum level because chloroplast of fully turgid leaves contain numerous starch granules and has minimum damage to thylakoid membrane structures. So, Quisenberry and McMicheal (1991) used the leaf turgidity for the selection of drought tolerant cotton plants.

\section{Relative water content (RWC)}

Water content and moisture content is quantity of water contained in soil, rocks, ceramics, fruits and in different tissues of the plants. Relative water content is used in wide range of scientific and technical area. Along with other indicators relative water content can also be used for the identification of drought resistant plants. It has been observed that the older leaves of Gossypium arboreum have relatively low water potential than that of younger leaves. It was further found that older leaves absorb relatively less water than that of younger one which results in the higher relative water content (Knipling, 1967). Similarly, it has been reported that progressive decline in RWC is because of drought stress in plants especially in Gossypium hirsutum (Ferreira et al., 1979). In another experiment Assaad and Signer found a positive relationship between RWC and leaf water content. They also co-relate it with genotype of cotton plants especially desi cotton. However, when the stress is disappeared, RWC progressively recovered within $48 \mathrm{~h}$ (Assaad and Signer, 1992).

\section{Cell membrane permeability}

Cell membrane is a biological membrane that separates the interior of cell from outside environment. It is a selectively permeable membrane which controls the movement of ions, organic molecules and other important substances (Choffnes et al., 2001). Its basic function is to protect the cell. Various other biochemical reactions are taking place on the interior surface of the cell membrane so, its stability is imperative for all metabolic reactions of the cell. Both biotic and abiotic stresses affect the stability of cell membrane (Kramer, 1979). Cell membrane stability is influenced by age of the plant, growing season, development of stage, degree of hardening, type of tissue culture and plant species. However, it is observed injury to plasma membrane because of drought stress in maize plants is much less severe in developing leaves as compared to mature leaves (Nath et al., 2005). It was also measured an increase in the saturated fatty acid under stress (Singh et al., 2015), which alleviates the melting point of plasma membrane and in turn reduce the stress tolerance in plant. Somerville and Browse, revealed that total lipid content of leaves in the membrane of Arabidopsis plant, growing under high temperature are decreased up to $1 / 2$ and ratio of the unsaturated to saturated fatty acid is also decreased up to $1 / 3$ of the normal temperature. It must be noted, here, that some species cannot co-relate with the degree of lipid saturation (Somerville and Browse, 1991). It was concluded that other factors for membrane stability are also involved along with the fluctuation in temperature. The relationship between the cell membrane stability and crop yield under drought condition may vary from plant to plant (Tanou et al., 2012). For example Showler, described such kind of relationship in few plants especially in sorghum (Showler, 2002). However, before Showler, Martin et al., were failed in defining such kind of relationship in soya bean plants. In short, it can be said that the major cause of yield suppression under drought stress is still obscure and deserve further experimentation (Martin et al., 1993). 


\section{Biochemical response of plants under drought stress}

\section{Proline content}

Proline is an essential amino acid, which is biosynthetically is derived from the glutamate. It is a major osmoregulant in plant tissues under drought conditions. Proline is produced in larger amount as compared to the normal conditions (Alamillo et al., 1995). It is considered as a compatible solute as well as osmo-protectant, which protects the plant tissues by producing stress responsive protein comparative analysis between CIM-496 G. hirsutum and FDH-786-G. arboreum (Khedr et al., 2003) in plants of $G$. arboreum. Kumar and his coworkers revealed that when water potential becomes the amount of osmolytes which are imperative for osmoregulation, allows additional water from environment. This helps in minimizing the immediate effect of drought stress (Kumar et al., 2003). Similarly, Unyayer and his coworkers, while studying the characteristics of Helianthus annus under drought condition observed a strong correlation between proline content and water deficiency (Ünyayar et al., 2004).

In another experiment the over production of proline in transgenic tobacco was reported, which resulted in increase in biomass of roots (Quisenberry et al., 1985). Similarly, Zhu and his colleagues performed experiment on transgenic rice plants, the conclusion showed that drought stress condition causes the decrease in biomass (Zhu et al., 1998). Other scientists around the world like in sorghum (Yadav et al., 2005), bell pepper (Nath et al., 2005), Gossypium hirsutum (Massacci et al., 2008), wheat (Hamada, 2000) and in Catharanthus roseus (Jaleel et al., 2009) found that amount of proline content increased under drought stress condition.

\section{Chlorophyll content}

Chlorophyll is a green pigment present in chloroplast of all green plants and tissues. It is essential for photosynthesis which has ability to absorb light energy and responsible for the carbohydrate metabolism. By measuring the chlorophyll content of a plant tissue, a reliable estimate of photosynthetic rate in green tissues of a plant can be gagged (Ackerson, 1981; Ali et al., 2017; Mahmood et al., 2017). Various studies by different scientists revealed that photosynthetic activity is decreased under drought stress. To prove this notion, Arnon and Whatley, performed experiment on $G$. barbadense, G. arboreum, G. herbaceum and G. hirsutum. It was also found that chlorophyll content, soluble sugar content and photosynthetic ratio is higher in $\mathrm{G}$. barbadense, which is followed by $G$. arboreum, $G$. herbaceum and significantly by $G$. hirsutum (Arnon and Whatley, 1949). Krasichkova and his colleagues observed that rate of photosynthetic activity and chlorophyll content is higher in high yielding cotton varieties (Krasichkova et al., 1989). It is observed that total chlorophyll content in $G$. arboreum is decreased with decreasing the soil water potential (Kvint et al., 2003). Similarly, it was also found that content of the chlorophyll $b$ is higher as compared to the chlorophyll a content in various cotton genotypes in drought condition (Burke et al., 1985). Kar and his colleagues while performing experiment on various lines of $G$. hirsutum plants; they maintained that chlorophyll $\mathrm{b}$ has affinity to clear weather condition. They also concluded that moisture deficit condition affects the total chlorophyll as well as proline content in G. hirsutum (Kar et al., 2001).

\section{Antioxidant enzymes}


Antioxidant enzymes in plant tissues, i.e. super oxide dismutase, catalases, glutathione, peroxidase and methadone reductase. An antioxidant is a molecule that inhibits the oxidation of other molecules. Oxidation is a metabolic reaction in which free radicals are produced. In turn these can start chain reactions which can damage or death to the cell. Antioxidant terminates these chain reactions by removing free radicals intermediates and inhibits other oxidation reactions (Wanner and Junttila, 1999). So, antioxidants are reducing agents. Drought stress in addition to dehydration also induces oxidative stress such as generation of active oxygen species (ROS) including super oxide radical $\left(\mathrm{O}^{2-}\right)$, nasent oxygen $(\mathrm{O})$, hydrogen peroxide $\left(\mathrm{H}_{2} \mathrm{O}_{2}\right)$, hydroxyl ion $\left(\mathrm{OH}^{-}\right)$. Their production is injurious to the cell (Nepomuceno et al., 1998). $\mathrm{Xu}$ and his colleagues revealed that antioxidant species cause the auto-catalytic oxidation of membrane lipids and pigments then leading to the loss of membrane semi permeability and modification in its functions. Among antioxidant species superoxide radical $\left(\mathrm{O}^{2-}\right)$ is regularly synthesized in a chloroplast and mitochondria (Xu et al., 2006). However, some of its quantity is also produced in micro-bodies. The quenching of super oxide radical by super oxide dismutase (SOD) results in production of hydrogen peroxide $\left(\mathrm{H}_{2} \mathrm{O}_{2}\right)$. However, both $\mathrm{O}^{2-}$ and $\mathrm{H}_{2} \mathrm{O}_{2}$ are not toxic to the cell as $\mathrm{OH}-$ is injurious to cell, which is formed by the combination of $\mathrm{O}^{2-}$ and $\mathrm{H}_{2} \mathrm{O}_{2}$ in the presence of trace amount of $\mathrm{Fe}^{2+}$ and $\mathrm{Fe}^{3+}$ (Monk et al., 1989). The $\mathrm{O}^{2-}$ can damage chlorophyll, protein, DNA, lipid and other important micro-molecules. Thus affect the plant metabolism and limit the crop yields. Sairam and Tyagi, found that plants have, developed a series of both enzymatic and non-enzymatic detoxification systems to counteract activated oxygen species (AOS), thereby protecting the cells from oxidative damage (Sairam and Tyagi, 2004). Similarly, it was also found by Kosmidou and his colleagues that various physiological and metabolic reactions have been affected by the over expression of super oxide dismutase (SOD) (Voloudakis et al., 2002).

\section{Molecular response of plants to drought stress}

The molecular details of a plant's response against stresses are complicated. These involve receptors, transcription factors, genes, noncoding RNAs, ions, and enzymes etc. Despite of the variability the plant response against a stress condition begins with the perception of the signal by specific receptors. Plants perceive dehydration by one of the following two mechanisms (Chaves et al., 2003). Through changes in osmotic potential; the membrane protein AtHK1 (Histidine Kinase 1) senses the change in osmotic potential produced inside the cell, while EcHKT1 works in the similar for sensing changes in extracellular environment. Through changes in membrane texture; the dehydration results in interaction of cationic and anionic amphiphilic substances which changes the membrane texture which is sensed by membranes proteins like OpuA. The above mentioned proteins initiate a series of signaling events. These involve many molecular respondents. Urao and his colleagues identified three phospho-relay intermediates (ATHP1-3) and four response regulators (ATRR1 -4). These molecules are supposed to play role in post perception events; however, their function is not yet clear (Urao et al., 2000). Post perception events are shown to include phosphorylation and dephosphorylation of phosphatases and changes in cytoplasmic Calcium concentration (Luan, 1998). These events then result in activation of various signaling cascades. These relative unclear cascades divide dehydration response in to branching one that involves $\mathrm{ABA}$ and the other which works independent of $\mathrm{ABA}$. ABA 
dependent responses are major cellular responses against stress. Two enzymes of ABA biosynthesis have been shown to respond to the cellular perception of stress namely these enzymes are Zeaxanthin epoxidase (ZEP) and 9-cis-epoxycarotenoid dioxygnase (NCED) (Qin and Zeevaart, 1999; Taylor et al., 2000). Stomata closure, maintenance of root growth and restricted leaf expansion are some of the many consequences of ABA activities in different organs of the plants. ABA mediated signaling cascades that make the mentioned things to happen were reviewed (Bray, 2002). ABA independent pathways are of limited importance for stress response. Mostly these involve genes which have conserved dehydration response element (DRE) in their promoters (Luan, 1998).

Cotton responds to stresses by bringing a large number of changes in its morphology and physiology. Tracking these changes down to molecular level leads to the conclusion that the basic framework of cotton response is similar to other plants but for the large part the specific effectors used by cotton are unique to this plant. ABA mediated responses remain an important part of cotton cells' response to osmotic stress; however, osmotin is shown to be a very important downstream target of ABA in cotton. This protein has binding sites of several TFs in its promoter and has capability to interact with different proteins hence working as a hub in molecular response to osmotic stress (Wilkinson et al., 1995). Trehalose 6 phosphate synthase gene is believed to be important in stress signal transduction suggesting that Trehalose 6 phosphate has a vital role as a secondary messenger in cotton (Kosmas et al., 2006). ABA mediated responses, for the large part, work by the involvement of calcium. In stressed cotton cells calcium based activities are mostly driven by calmodulins. Owing to the importance of calmodulins cotton produce a specific heat shock protein named Heat Shock Protein Camodulin Binding (HSPCB). This protein has the duty to bind with calmodulin and keep it active so that it is able to play its role efficiently (Voloudakis et al., 2002).

\section{Contribution of genetic engineering to drought tolerance}

Drought tolerant genes have been identified while investigating the molecular mechanisms of plants response to drought stress. These genes were isolated and characterized by transferring them into drought prone plant species. This approach in some cases has been found successful to increase agronomic performance and crop yield. A good example of this success story is transgenic wheat expressing HVA1 gene from barley, encoding late embryogenesis abundant (LEA) proteins. Results showed that the HVA1 protein confers a significant protection from drought stress (Bahieldin et al., 2015). Aquaporins mediate symplastic water transportation in plants could be a limiting factor for growth under unfavorable environmental conditions. Differential expression of these genes during plant development that encode for aquaporins has been observed to be associated with various physiological processes. Such processes include opening and closing of stomata, cell elongation, cell division and organ movement (Berriman et al., 2009). The SITIP-2 gene coding aquaporin protein was found predominantly effective to improve drought stress tolerance in tomato plants (Hajheidari et al., 2005). Another successful gene is OsNAC10, introduced in rice plants under the control of GOS2 constitutive promoter and RCc3 root-specific promoter (Tang and Page, 2013). 


\section{Gene cloning and expression}

Gene cloning and expression makes it possible to transfer biological properties from one organism to another. This exciting field of research owes its spectacular development to emergence of tools for DNA manipulation, enhancements and extensions in the existing knowledge, novel ways that investigators are using to apply the available technologies and finally the rapid pace with which research is being carried out in this field. The idea of transferring a gene between organisms was first conceived and materialized in the decade of 1970. Phages have the ability to transfer portions of DNA between bacteria through generalized or specialized transduction mechanisms. It was reported in early 1970 s that some linear phage DNAs contain sticky ends on their terminals and that in some abnormal conditions a linear phage DNA may be separated into two or more pieces while retaining the sticky in their original positions. In their first effort to attach two DNA fragments investigators used TdT, an enzyme which adds poly A or poly $\mathrm{T}$ tails to 3 ' blunt ends, and DNA ligase. A small part of bacterial DNA was isolated and it was treated with TdT similarly two fragments of phage DNA were treated with complementary TdT and finally these three fragments were ligated with DNA ligase. This experiment resulted in the creation of a circular phage DNA containing a bacterial DNA fragment in it. The hence produced circular phage DNA was found to be the target of restriction enzyme EcoRI which was observed to cut this circular DNA on one place and make it linear. In final step this EcoRI cut linear phage DNA was ligated with a similarly prepared phage DNA containing antibiotic resistance gene (Berg and Mertz, 2010).

\section{Universal stress protein (USP)}

A protein that contains a USP domain (a characteristic USP structure) is be referred to as a universal stress protein (USP). A USP may contain one or more USP domains a fact that allows USPs to perform a board range of functions (Isokpehi et al., 2011). USP gene was first discovered in bacteria via 2D gel electrophoresis and was named as C13.5 based on its migration during 2D experiment. Later studies recognized these proteins as part of all stress and starvation stimulus known at that time and thus these were renamed as Universal Stress Proteins (Kvint et al., 2003). USP genes are involved in wide range of metabolic activities. These have been described to play role in bacterial virulence, heat shock, cold shock, DNA management and metabolic control (Persson et al., 2007; Loukehaich et al., 2012). In most cases the mechanisms of functions performed by USPs are still undiscovered but for a few functions some information is gathered about the mechanisms. When a plant is subjected to water stress, ABA level is increased which resulted in expression of USP genes. This is consistent with the finding that USPs can bind with transcription factors (Gury et al., 2009). One of the two activated gene clusters produces LHCB (Light Harvesting Chlorophyll a/b Binding) proteins. LHCB keeps the chloroplasts intact and reduces the stomatal aperture to preserve water during water stress. The second gene cluster produces some osmoprotective solutes, e.g. proline which protects the cells from harmful effects of ROSs (Loukehaich et al., 2012). In water stress USP is believed to interact with Annexin protein but the details about how actually the USP performs its functions are still to be elucidated.

E coli responds to salt stress by producing an ion transporter called (KdpFABC) which transports the extra salt ions out of the bacterial cell. The production of this 
transporter comes after induction of its gene with a complex of $\mathrm{KdpD}$ and $\mathrm{KdpE}$. This complex is only formed when $\mathrm{KdpE}$ is phosphorylated. In excess ions $\mathrm{KdpE}$ phosphorylation is inhibited. Here USP comes to play its part such as USP phosphorylates the $\mathrm{KdpE}$ and then hold it with $\mathrm{KdpD}$ forming the complex which induces the production of KdpFABC (Heermann et al., 2009). Another similar mechanism is also described in Halomonas elongate. Here the USP instead of inducing the expression of transporter binds itself with the transporter named TeaABC making it active. The study on $\mathrm{H}$. elongate TeaABC and USP interaction stresses on the assertion that ATP binding USP does not play any role in transcription regulation (Huang et al., 2012). Owing to their importance several studies have been conducted to find out the structure of USPs. These investigations reveal that the structure of USP remains similar in different organisms. A USP contains an ATP binding motif at its N-terminal while the C-terminal region takes different forms depending upon the context of the protein. In many proteins the C-terminal region also binds with an ATP molecule making USP capable of binding with two ATPs at a time (Gonzali et al., 2015). The N-terminal ATP binding motif in various USPs have high \% of glycine amino acids which allow USPproteins to attach with ATP molecules (Drumm et al., 2009).

\section{Plant transformation}

Conventional breeding methods were slow and laborious; to beat these limitations plant transformation methods were developed for the production of genetically engineered plants. Through transformation gene of interest can be introduced into plants without altering their vital characters. Plant transformation method is the set of events used to introduce a fragment of DNA, having specific trait, into host plant. By utilizing this method plants are engineered to produce new varieties with desirable traits. It can be achieved either by Agrobacterium tumefacien-mediated transformation or by gold particle bombardment. In the first method plant cells are infected with pathogenic Agrobacterium tumefaciens bacterium possessing the desired gene. In the later procedure gene gun is used for the gene coded bombardment of particles. Both of these methods are extensively used in research applications (Somerville and Browse, 1991; Tinland, 1996; Tzfira et al., 2004).

\section{Agrobacterium-mediated transformation}

Agrobacterium tumefaciens-mediated transformation is leading technology used for production of transgenic plants. The genus Agrobacterium has been classified into various species because of its disease symptomology and host range (Otten et al., 1984). A. tumefacien, naturally present in soil, it penetrates in plants at wound sites and initiates the formation of tumor, disease commonly known as crown gall (Smith and Townsend, 1907). The crown gall disease has been observed because of the transfer of T-DNA (transfer DNA) from tumor-inducing (Ti) plasmid from A. tumefaciens to plant cells (Zaenen et al., 1974) and integrated into plant genome (Chilton and Que, 2003). Two genetic elements are required for transfer of T DNA to plants. The first element is $25 \mathrm{bp}$ direct repeats defining and flanking region of T-DNA border sequence (Zambryski et al., 1983). The second element virulence genes (vir) encoded by the TiPlasmid in a region present outside of the T-DNA region. The vir genes encode a set of proteins responsible for the excision, transfer and integration of the T-DNA into the plant genome. In plant transformation, use of T-DNA process is because of three facts. 
Firstly, the tumor is formed that resulted from integration of T-DNA and its subsequent expression Secondly, the T-DNA genes do not play role during their transfer process, they are only transcribed inside plant cells. Thirdly, any gene of interest placed between T-DNA borders can be transferred to plant cell.

\section{Cellular localization of gene expression}

Eukaryotic cell organelles are membrane bounded there for various cellular activities are restricted to specific well defined organelle inside the cell. These cell organelles have been studied via cell fractionation method and by analyzing samples of fixed tissues. Information about localization of sub-cellular protein is first footstep towards understanding its function (Kokkirala et al., 2010) and this process direct the retention and transportation of protein complexes into tissue specific location. It is imperative to understand complex metabolic processes in various plant tissues such as fruits, roots stem and leaves. To study the metabolism in abundant plant tissues is comparatively easy, because the whole tissue can be used as the sample while, less abundant plant tissues are difficult to be used as sample because their basic metabolic reactions are masked by more abundant plant tissues (Carrigan et al., 2011). It is also difficult in case of plants to understand the specific function of single protein due to the presence of multi gene families. So, it is imperative to compare among different patterns of multi gene families at sub-cellular level (Hanson and Köhler, 2001).

The cellular location of different regulatory proteins and enzymes in plant cells during different stages of development, under diverse environmental circumstances is indicated its functional pathway. Mostly, prediction models of bioinformatics are used for location of different proteins. Moreover, localization of several plant proteins has been found at numerous cellular regions (Small et al., 1998). Green fluorescent protein is green light emitting protein, when it is excited with lower wavelength light. Light emitting proteins also know as fluorescent proteins (FPs), they are classified as brand range family of fluorescent proteins and GFP-proteins belong to this family. Now GFPs are being used in various applications of molecular biology (Zhang et al., 2002). Common use of fluorescent protein has one main advantage of its normal light emitting process with involvement of any enzyme or substrate (Ei-Shemy et al., 2009).

\section{Green fluorescent proteins (GFPs)}

Green fluorescent protein is a green light emitting protein, when it is excited with lower wavelength light. Now GFPs are being used in various applications of molecular biology (Zhang et al., 2002). Common use of fluorescent protein has one main advantage of its normal light emitting process with involvement of any enzyme or substrate (Ei-Shemy et al., 2009). The 238 amino acids long GFP has a tightly closed structure which is found to be conserved in all different types of FPs characterized so far. Truncation studies show that about 7 amino acids from $\mathrm{C}$ - terminal and only the first methionine from $\mathrm{N}$-terminal can be removed without abolishing the GFP function. This signifies that most of the structure of GFP is important for development and maintenance of fluorescence. GFPs (like all FPs) consist of 11 beta sheets, small alpha helices and some irregular peptides. The beta sheets come together and form a rigid structure which is known as "Beta Barrel". The beta sheets in a barrel are connected with each other through small helices and flexible proline rich peptides. In addition an 
alpha helix is present in the center of the beta barrel. This helix contains a highly conserved sequence of three amino acids which come together and form the structure which is responsible for the production of fluorescence (Khedr et al., 2003). The structure thus formed is termed as chromophore (sometimes as fluorophore). The location of chromophore in GFP is very important for its function. The beta barrel has polar amino acids branching out towards the chromophore and hold water molecules hence producing an environment for chromophore to exhibit fluorescence. In addition the barrel also protects the chromophore from the outside environment (Zhang et al., 2002; Foolad, 2004). The native GFP which was isolated from Aequorea Victoria is found to be of just a little usage. Research carried out on GFP resulted in modification of native GFP to produce a broad range of derivatives which can be used more readily in the molecular biology applications. These new derivatives of GFP have some properties to make them suitable. The modifications introduced in GFPs along with the resultant properties can be categorized into following categories:

The modification made in the chromophore sequence result in the production of different coloured GFP derivatives. Such changes in the sequence produce different energy states of chromophore as compare to the native, which are capable of emitting light of different wavelengths (producing colours other than green). By using same mechanism, the chromophore modifications can also alter the excitation wavelength of the native GFP hence producing derivatives which absorb different wavelengths while producing same colour (Foolad, 2004). This kind of shift is especially helpful in fine tuning the GFP for the fluorescence detection system present in place. In addition, change in chromophore sequence also is shown to be associated with increased emission of a particular wavelength, i.e. increased luminescence (Berriman et al., 2009).

\section{Site directed mutagenesis}

Point mutation or site directed mutagenesis has been used to ascertain the function of unknown gene; this technique causes alteration at specific point in the sequence of a gene. This is also known as oligonucleotide directed mutagenesis. Point mutations can be randomly inserted in the whole sequence of gene at multiple locations or it can be specifically integrated at predetermined location by site directed mutagenesis (Sturm, 2009). It can be carried out both in-vivo and in-vitro. Model organisms are used in case of in-vivo while plasmid constructs are used in case of later. To ascertain the importance of amino acids and their function in protein structure, site directed mutagenesis has been used extensively (Kunkel et al., 1991; Ishii et al., 1998). It can be utilized to study protein function and structural relationship, protein binding sites, active sites present in enzymes, gene characterization and protein-protein interaction.

To alter the sequence of gene of interest, synthetic oligonucleotides are extensively used in research. Numerous protocols have been used and for this purpose while PCRmediated site directed mutagenesis was found efficient most common method (Saiki et al., 1985). For this purpose two complementary mutagenic primers (40 bp long) with mutated nucleotide in its center are designed by using online software (Zhang et al., 2015). Laible and Boonrod carried out site directed mutagenesis of whole plasmid by using non-PCR thermo cycling reaction. This technique was used to produce mutated enzyme to wipe out its enzymatic activity to utilize as experimental model (Laible and Boonrod, 2009). Dipetarudin protease is potent inhibitor of thrombin it inhibits the 
normal function of trypsin and plasmin (Lopez-Molina et al., 2002). When single amino

acid (Arginine-10) was replace by histidine then mutant form, dipetarud in $\mathrm{R} 10 \mathrm{H}$, had lostits activity to inhibit plasmin and trypsin as compared to wild type. In the beginning, artificial oligonucleotides were being used for the rectification of site directed mutagenesis in $\beta$-globin gene which causes sickle cell anemia (Saiki et al., 1985). Rectification of sickle cell anemia was a turning point in commercializing this technology (Saiki et al., 1985; Zhang et al., 1995; Beetham et al., 1999; Zhu et al., 2000).

Initially, site directed mutagenesis was used in tobacco and corn, model species. Point mutation in acetohydroxy acid synthase I andIII genes, at specific sites made them resistant agaist herbicide both in corn and tobacco (Zhang et al., 2015). Endo and his colleagues mutated acetolactate Synthase (ALS) gene of rice at specific point by using site directed mutagenesis and developed resistance against bispyribac herbicide. They reported that change in two amino acids separately in two different clones causes tolerance in bispyribac herbicide. These two amino acids are Serine and Tryptophan which replaced with Isoleucine and Leucine respectively (Endo et al., 2007). However, if both amino acids will change at a time then it confers bispyribac herbicide resistance to plant. This technique has broad range of applications because it can create several mutations, insertions and deletions. This can also be used for the characterization of unknown genes responsible for fatal diseases. Now commercial kits are easily available which makes it faster, reliable and efficient (Carrigan et al., 2011). This technique has been utilized for the customization of various crops for introduction of desired traits and for increase per capita yield.

\section{Conclusion}

In view of above discussion it can be concluded that drought stress affect morphological, physiological, biochemical and molecular traits of cotton plants which became the major cause of yield reduction. Drought stress is important threat among abiotic stresses, which has drastic affects on normal growth of plants. It is considered as major reason to low productivity of cotton in Pakistan and situation could worse in future because depleting irrigation capacity. Drought stress is natural and spontaneous it cannot be controlled with either synthetic chemicals or skilled agricultural practices. Modern view about control of drought stress is production of transgenic crops having tolerance towards drought stress. Drought tolerance mechanism is controlled by multiple genes, so, manipulation of one or two drought stress related gene could not be much effective. It is need of hour to understand the cellular mechanism of drought tolerance for future engineering of tolerant plants. USP genes have been identified in one variety of cotton which could be manipulated for drought tolerant transgenic cotton plants with high yielding as well. Several soluble sugars and stress proteins have been reported to act as protectant under drought stress and universal stress protein (USP) is the most important family of proteins in this regard. This family encompasses a conserved and ancient group of proteins that are present and has been reported in different organisms including cotton, where they are playing role in response to heat 
shock, cold shock, DNA management, metabolic control. Furthermore, USP is a regulatory unit protein; its activity can be increased by manipulating its interactions.

Author contribution statement. MNH wrote the initial draft of manuscript. MNH and QA edited the manuscript and made minor corrections. QA made final editing and corrections in manuscript to make it in its final version to be published. All of the authors have proof-read the manuscript before submission. The final approval for publication was given by BR.

Conflict of interests. The authors declared that there is no conflict of interests for the manuscript.

\section{REFERENCES}

[1] Ackerson, R. C. (1981): Osmoregulation in cotton in response to water stress ii. Leaf carbohydrate status in relation to osmotic adjustment. - Plant Physiology 67(3): 489-493.

[2] Alamillo, J., Almoguera, C., Bartels, D., Jordano, J. (1995): Constitutive expression of small heat shock proteins in vegetative tissues of the resurrection plant craterostigma plantagineum. - Plant Molecular Biology 29(5): 1093-1099.

[3] Ali, F., Ahsan, M., Ali, Q., Kanwal, N. (2017): Phenotypic stability of zea mays grain yield and its attributing traits under drought stress. - Frontiers in Plant Science 8: 1397.

[4] Ali, Q., Ahsan, M., Ali, F., Aslam, M., Khan, N. H., Munzoor, M., Mustafa, H. S. B., Muhammad, S. (2013): Heritability, heterosis and heterobeltiosis studies for morphological traits of maize (Zea mays L.) seedlings. - Advancements in Life Sciences 1(1) 52-63.

[5] Ali, Q., Ali, A., Ahsan, M., Ali, S., Khan, N. H., Muhammad, S., Abbas, H. G., Nasir, I. A., Husnain, T. (2014): Line $\times$ Tester analysis for morpho-physiological traits of Zea mays L. seedlings. - Advancements in Life Sciences 1(4): 242-253.

[6] Ali, Q., Ahsan, M., Malook, S., Kanwal, N., Ali, F., Ali, A., Ahmed, W., Ishfaq, M., Saleem, M. (2016): Screening for drought tolerance: comparison of maize hybrids under water deficit condition. - Advancements in Life Sciences 3(2): 51-58.

[7] Altaf-Khan, M., Myers, G., Stewart, J. (2002): Molecular Markers, Genomics and Cotton Improvement. - In: Kang, M. S. (ed.) Crop Improvement Challenges in the Twenty First Century. CRC, Boca Raton, FL, pp. 253-284.

[8] Arnon, D. I., Whatley, F. (1949): Is chloride a coenzyme of photosynthesis? - Science 110(2865): 554-556.

[9] Ashraf, M., Foolad, M. (2007): Roles of glycine betaine and proline in improving plant abiotic stress resistance. - Environmental and Experimental Botany 59(2): 206-216.

[10] Assaad, F. F., Signer, E. R. (1992): Somatic and germinal recombination of a direct repeat in arabidopsis. - Genetics 132(2): 553-566.

[11] Bahieldin, A., Atef, A., Shokry, A. M., Al-Karim, S., Al, S. G. Attas, Gadallah, N. O., Edris, S., Al-Kordy, M. A., Omer, A. M. S., Sabir, J. S. (2015): Structural identification of putative usps in catharanthus roseus. - Comptes Rendus Biologies 338(10): 643-649.

[12] Bayley, C., Trolinder, N., Ray, C., Morgan, M., Quisenberry, J., Ow, D. (1992): Engineering 2, 4-d resistance into cotton. - Theoretical and Applied Genetics 83(5): 645649.

[13] Beetham, P. R., Kipp, P. B., Sawycky, X. L., Arntzen, C. J., May, G. D. (1999): A tool for functional plant genomics: Chimeric rna/DNA oligonucleotides cause in vivo genespecific mutations. - Proceedings of the National Academy of Sciences 96(15): 87748778.

[14] Berg, P., Mertz, J. E. (2010): Personal reflections on the origins and emergence of recombinant DNA technology. - Genetics 184(1): 9-17. 
[15] Berriman, M., Haas, B. J., LoVerde, P. T., Wilson, R. A., Dillon, G. P., Cerqueira, G. C., Mashiyama, S. T., Al-Lazikani, B., Andrade, L. F., Ashton, P. D. (2009): The genome of the blood fluke schistosoma mansoni. - Nature 460(7253): 352-358.

[16] Bhatt, R., Rao, N. S. (2005): Influence of pod load on response of okra to water stress. Indian Journal of Plant Physiology 10(1): 54.

[17] Bray, E. (2002): Abscisic acid regulation of gene expression during water $\square$ deficit stress in the era of the arabidopsis genome. - Plant, Cell and Environment 25(2): 153-161.

[18] Burke, J. J., Hatfield, J. L., Klein, R. R., Mullet, J. E. (1985): Accumulation of heat shock proteins in field-grown cotton. - Plant Physiology 78(2): 394-398.

[19] Carrigan, P. E., Ballar, P., Tuzmen, S. (2011): Site-directed mutagenesis. - Disease Gene Identification: Methods and Protocols: 107-124.

[20] Chaves, M. M., Maroco, J. P., Pereira, J. S. (2003): Understanding plant responses to drought - from genes to the whole plant. - Functional Plant Biology 30(3): 239-264.

[21] Chaves, M. M., Flexas, J., Pinheiro, C. (2009): Photosynthesis under drought and salt stress: Regulation mechanisms from whole plant to cell. - Annals of Botany 103(4): 551560 .

[22] Chilton, M.-D. M., Que, Q. (2003): Targeted integration of t-DNA into the tobacco genome at double-stranded breaks: New insights on the mechanism of t-DNA integration. - Plant Physiology 133(3): 956-965.

[23] Choffnes, D., Philip, R., Vodkin, L. (2001): A transgenic locus in soybean exhibits a high level of recombination. - In Vitro Cellular \& Developmental Biology-Plant 37(6): 756762.

[24] Degenkolbe, T., Do, P. T., Zuther, E., Repsilber, D., Walther, D., Hincha, D. K., Köhl, K. I. (2009): Expression profiling of rice cultivars differing in their tolerance to long-term drought stress. - Plant Molecular Biology 69(1-2): 133-153.

[25] Drumm, J. E., Mi, K., Bilder, P., Sun, M., Lim, J., Bielefeldt-Ohmann, H., Basaraba, R., So, M., Zhu, G., Tufariello, J. M. (2009): Mycobacterium tuberculosis universal stress protein rv2623 regulates bacillary growth by atp-binding: Requirement for establishing chronic persistent infection. - PLoS Pathogens 5(5): e1000460.

[26] Ei-Shemy, H. A., Khalafalla, M. M., Ishimoto, M. (2009): The role of green fluorescent protein (gfp) in transgenic plants to reduce gene silencing phenomena. - Current Issues in Molecular Biology 11(1): I21.

[27] Endo, M., Osakabe, K., Ono, K., Handa, H., Shimizu, T., Toki, S. (2007): Molecular breeding of a novel herbicide $\square$ tolerant rice by gene targeting. - The Plant Journal 52(1): 157-166.

[28] Fahramand, M., Mahmoody, M., Keykha, A., Noori, M., Rigi, K. (2014): Influence of abiotic stress on proline, photosynthetic enzymes and growth. - Int Res J Appl Basic Sci 8(3): 257-265.

[29] Farooq, M., Wahid, A., Kobayashi, N., Fujita, D., Basra, S. (2009): Plant drought stress: Effects, mechanisms and management. - Agronomy for Sustainable Development 29(1): 185-212.

[30] Ferreira, L. G., De Souza, J. G., Prisco, J. T. (1979): Effects of water deficit on proline accumulation and growth of two cotton genotypes of different drought resistances. Zeitschrift für Pflanzenphysiologie 93(3): 189-199.

[31] Filippou, P., Antoniou, C., Fotopoulos, V. (2011): Effect of drought and rewatering on the cellular status and antioxidant response of Medicago truncatula plants. - Plant Signaling \& Behavior 6(2): 270-277.

[32] Foolad, M. (2004): Recent advances in genetics of salt tolerance in tomato. - Plant Cell, Tissue and Organ Culture 76(2): 101-119.

[33] Gazanchian, A., Hajheidari, M., Sima, N. K., Salekdeh, G. H. (2007): Proteome response of elymus elongatum to severe water stress and recovery. - Journal of Experimental Botany 58(2): 291-300. 
[34] Golldack, D., Li, C., Mohan, H., Probst, N. (2014): Tolerance to drought and salt stress in plants: Unraveling the signaling networks. - Frontiers in Plant Science 5.

[35] Gonzali, S., Loreti, E., Cardarelli, F., Novi, G., Parlanti, S., Pucciariello, C., Bassolino, L., Banti, V., Licausi, F., Perata, P. (2015): Universal stress protein hru1 mediates ros homeostasis under anoxia. - Nature Plants 1: 15151.

[36] Gury, J., Seraut, H., Tran, N. P., Barthelmebs, L., Weidmann, S., Gervais, P., Cavin, J.-F. (2009): Inactivation of padr, the repressor of the phenolic acid stress response, by molecular interaction with usp1, a universal stress protein from lactobacillus plantarum, in escherichia coli. - Applied and Environmental Microbiology 75(16): 5273-5283.

[37] Gustavsson, N., Nyström, T. (2002): The universal stress protein paralogues of escherichia coli are co $\square$ ordinately regulated and co $\square$ operate in the defence against DNA damage. - Molecular Microbiology 43(1): 107-117.

[38] Hajheidari, M., Abdollahian $\square$ Noghabi, M., Askari, H., Heidari, M., Sadeghian, S. Y., Ober, E. S., Salekdeh, G. H. (2005): Proteome analysis of sugar beet leaves under drought stress. - Proteomics 5(4): 950-960.

[39] Hamada, A. (2000): Amelioration of drought stress by ascorbic acid, thiamin or aspirin in wheat plants. - Indian Journal of Plant Physiology 5(4): 358-364.

[40] Hanson, M. R., Köhler, R. H. (2001): Gfp imaging: Methodology and application to investigate cellular compartmentation in plants. - Journal of Experimental Botany 52(356): 529-539.

[41] Hayano-Kanashiro, C., Calderón-Vázquez, C., Ibarra-Laclette, E., Herrera-Estrella, L., Simpson, J. (2009): Analysis of gene expression and physiological responses in three mexican maize landraces under drought stress and recovery irrigation. - PLoS One 4(10): e7531.

[42] He, R., Kim, M.-J., Nelson, W., Balbuena, T. S., Kim, R., Kramer, R., Crow, J. A., May, G. D., Thelen, J. J., Soderlund, C. A. (2012): Next-generation sequencing-based transcriptomic and proteomic analysis of the common reed, phragmites australis (poaceae), reveals genes involved in invasiveness and rhizome specificity. - American Journal of Botany 99(2): 232-247.

[43] Heermann, R., Weber, A., Mayer, B., Ott, M., Hauser, E., Gabriel, G., Pirch, T., Jung, K. (2009): The universal stress protein uspc scaffolds the $\mathrm{kdpd} / \mathrm{kdpe}$ signaling cascade of escherichia coli under salt stress. - Journal of Molecular Biology 386(1): 134-148.

[44] Heuer, B., Nadler, A. (1998): Physiological response of potato plants to soil salinity and water deficit. - Plant Science 137(1): 43-51.

[45] Huang, B., Liu, J.-Y. (2006): A cotton dehydration responsive element binding protein functions as a transcriptional repressor of dre-mediated gene expression. - Biochemical and Biophysical Research Communications 343(4): 1023-1031.

[46] Huang, G.-T., Ma, S.-L., Bai, L.-P., Zhang, L., Ma, H., Jia, P., Liu, J., Zhong, M., Guo, Z.-F. (2012): Signal transduction during cold, salt, and drought stresses in plants. Molecular Biology Reports 39(2): 969-987.

[47] Ishii, T. M., Zerr, P., Xia, X.-M., Bond, C. T., Maylie, J., Adelman, J. P. (1998): Sitedirected mutagenesis. - Methods in Enzymology 293: 53-71.

[48] Isokpehi, R. D., Mahmud, O., Mbah, A. N., Simmons, S. S., Avelar, L., Rajnarayanan, R. V., Udensi, U. K., Ayensu, W. K., Cohly, H. H., Brown, S. D. (2011): Developmental regulation of genes encoding universal stress proteins in Schistosoma mansoni. - Gene Regulation and Systems Biology 5: 61.

[49] Jaleel, C. A., Manivannan, P., Sankar, B., Kishorekumar, A., Gopi, R., Somasundaram, R., Panneerselvam, R. (2007): Water deficit stress mitigation by calcium chloride in catharanthus roseus: Effects on oxidative stress, proline metabolism and indole alkaloid accumulation. - Colloids and Surfaces B: Biointerfaces 60(1): 110-116.

[50] Jaleel, C. A., Sankar, B., Murali, P., Gomathinayagam, M., Lakshmanan, G., Panneerselvam, R. (2008): Water deficit stress effects on reactive oxygen metabolism in 
Catharanthus roseus; impacts on ajmalicine accumulation. - Colloids and Surfaces B: Biointerfaces 62(1): 105-111.

[51] Jaleel, C. A., Manivannan, P., Wahid, A., Farooq, M., Al-Juburi, H. J., Somasundaram, R., Panneerselvam, R. (2009): Drought stress in plants: a review on morphological characteristics and pigments composition. - Int J Agric Biol 11(1): 100-105.

[52] Kar, M., Patro, B., Sahoo, C., Patel, S. (2001): Response of hybrid cotton to moisture stress. - Indian Journal of Plant Physiology 6(4): 427-430.

[53] Kawakami, E. M., Oosterhuis, D. M., Snider, J. L. (2010): Physiological effects of 1methylcyclopropene on well-watered and water-stressed cotton plants. - Journal of Plant Growth Regulation 29(3): 280-288.

[54] Khedr, A, A. H.., M. A. Abbas, Wahid, A. A. A., Quick, W. P., Abogadallah, G. M. (2003): Proline induces the expression of salt $\square$ stress $\square$ responsive proteins and may improve the adaptation of pancratium maritimum 1. To salt $\square$ stress. - Journal of Experimental Botany 54(392): 2553-2562.

[55] Knipling, E. B. (1967): Effect of leaf aging on water deficit-water potential relationships of dogwood leaves growing in two environments. - Physiologia Plantarum 20(1): 65-72.

[56] Kogan, F., Adamenko, T., Guo, W. (2013): Global and regional drought dynamics in the climate warming era. - Remote Sensing Letters 4(4): 364-372.

[57] Kokkirala, V. R., Yonggang, P., Abbagani, S., Zhu, Z., Umate, P. (2010): Subcellular localization of proteins of Oryza sativa L. In the model tobacco and tomato plants. - Plant Signaling and Behavior 5(11): 1336-1341.

[58] Koroleva, O. A., Tomlinson, M. L., Leader, D., Shaw, P., Doonan, J. H. (2005): High $\square$ throughput protein localization in arabidopsis using agrobacterium $\square$ mediated transient expression of gfp $\square$ orf fusions. - The Plant Journal 41(1): 162-174.

[59] Kosmas, S. A., Argyrokastritis, A., Loukas, M. G., Eliopoulos, E., Tsakas, S., Kaltsikes, P. J. (2006): Isolation and characterization of drought-related trehalose 6-phosphatesynthase gene from cultivated cotton (Gossypium hirsutum L.). - Planta 223(2): 329-339.

[60] Kramer, P. J. K. (1979): Physiology of Woody Plants. - Academic Press, New York.

[61] Krasichkova, G., Asoeva, L., Giller, Y., Singinov, B. (1989): Photosynthetic system of g. Barbadanse at the early stages of development. - Doklady Vsesovuznoi Ordena Trudovogo Krasnogo Znameni Akademii Sel Skokhozya Istvennykh Nauk Imen VI Lemina 12: 9-11.

[62] Krieg, D. R. (1983): Photosynthetic activity during stress. - Agricultural Water Management 7(1-3): 249-263.

[63] Kumar, S. G., Reddy, A. M., Sudhakar, C. (2003): Nacl effects on proline metabolism in two high yielding genotypes of mulberry (Morus alba L.) with contrasting salt tolerance. - Plant Science 165(6): 1245-1251.

[64] Kunkel, T. A., Bebenek, K., McClary, J. (1991): Efficient site-directed mutagenesis using uracil-containing DNA. - Methods in Enzymology 204: 125-139.

[65] Kvint, K., Nachin, L., Diez, A., Nyström, T. (2003): The bacterial universal stress protein: Function and regulation. - Current Opinion in Microbiology 6(2): 140-145.

[66] Laible, M., Boonrod, K. (2009): Homemade site directed mutagenesis of whole plasmids. - Journal of Visualized Experiments: JoVE(27).

[67] Liu, D., Guo, X., Lin, Z., Nie, Y., Zhang, X. (2006): Genetic diversity of asian cotton (Gossypium arboreum L.) in china evaluated by microsatellite analysis. - Genetic Resources and Crop Evolution 53(6): 1145-1152.

[68] Lopez $\square$ Molina, L., Mongrand, S., McLachlin, D. T., Chait, B. T., Chua, N. H. (2002): Abi5 acts downstream of abi3 to execute an aba $\square$ dependent growth arrest during germination. - The Plant Journal 32(3): 317-328.

[69] Loukehaich, R., Wang, T., Ouyang, B., Ziaf, K., Li, H., Zhang, J., Lu, Y., Ye, Z. (2012): Spusp, an annexin-interacting universal stress protein, enhances drought tolerance in tomato. - Journal of Experimental Botany 63(15): 5593-5606. 
[70] Luan, S. (1998): Protein phosphatases and signaling cascades in higher plants. - Trends in Plant Science 3(7): 271-275.

[71] Mahmood, A., Haider, M. S., Ali, Q., Nasir, I. A. (2017): Multivariate analysis to assess abscisic acid content association with different physiological and plant growth related traits of petunia. - Acta Agriculturae Slovenica 109(2): 175-186.

[72] Malik, C. P., Srivastava, A. K. (1979): Text Book of Plant Physiology. - Kalyani Publishers, New Dehli, pp. 3-41.

[73] Manivannan, P., Jaleel, C. A., Sankar, B., Kishorekumar, A., Somasundaram, R., Lakshmanan, G. A., Panneerselvam, R. (2007): Growth, biochemical modifications and proline metabolism in Helianthus annuus L. As induced by drought stress. - Colloids and Surfaces B: Biointerfaces 59(2): 141-149.

[74] Mansoor, S., Amin, I., Iram, S., Hussain, M., Zafar, Y., Malik, K., Briddon, R. (2003): Breakdown of resistance in cotton to cotton leaf curl disease in pakistan. - Plant Pathology 52(6): 784-784.

[75] Maqbool, A., Zahur, M., Husnain, T., Riazuddin, S. (2009): Gusp1 and gusp2, two drought-responsive genes in gossypium arboreum have homology to universal stress proteins. - Plant Molecular Biology Reporter 27(1): 109-114.

[76] Martin, M., Miceli, F., Morgan, J., Scalet, M., Zerbi, G. (1993): Synthesis of osmotically active substances in winter wheat leaves as related to drought resistance of different genotypes. - Journal of Agronomy and Crop Science 171(3): 176-184.

[77] Massacci, A., Nabiev, S., Pietrosanti, L., Nematov, S., Chernikova, T., Thor, K., Leipner, J. (2008): Response of the photosynthetic apparatus of cotton (gossypium hirsutum) to the onset of drought stress under field conditions studied by gas-exchange analysis and chlorophyll fluorescence imaging. - Plant Physiology and Biochemistry 46(2): 189-195.

[78] Mbah, A. N., Mahmud, O., Awofolu, O. R., Isokpehi, R. D. (2013): Inferences on the biochemical and environmental regulation of universal stress proteins from schistosomiasis parasites. - Advances and Applications in Bioinformatics and Chemistry: AABC 6: 15.

[79] Mehetre, S., Aher, A., Gawande, V., Patil, V., Mokate, A. (2003): Induced polyploidy in gossypium: A tool to overcome interspecific incompatibility of cultivated tetraploid and diploid cottons. - Current Science 84(12): 1510-1512.

[80] Monk, L. S., Fagerstedt, K. V., Crawford R. M. (1989): Oxygen toxicity and superoxide dismutase as an antioxidant in physiological stress. - Physiologia Plantarum 76(3): 456459.

[81] Morgan, J. M. (19840: Osmoregulation and water stress in higher plants. - Annual Review of Plant Physiology 35(1): 299-319.

[82] Nakabayashi, R., Yonekura $\square$ Sakakibara, K., Urano, K., Suzuki, M., Yamada, Y., Nishizawa, T., Matsuda, F., Kojima, M., Sakakibara, H., Shinozaki, K., Michael, A. J. (2014): Enhancement of oxidative and drought tolerance in Arabidopsis by overaccumulation of antioxidant flavonoids. - The Plant Journal 77(3), pp.367-379.

[83] Nath, A. K., Kumari, S., Sharma, D. (2005): In vitro selection and characterization of water stress tolerant cultures of bell pepper. - Indian Journal of Plant Physiology 10(1): 14-19.

[84] Nepomuceno, A., Oosterhuis, D., Stewart, J. (1998): Physiological responses of cotton leaves and roots to water deficit induced by polyethylene glycol. - Environmental and Experimental Botany 40(1): 29-41.

[85] Otten, L., De, H. Greve, Leemans, J., Hain, R., Hooykaas, P., Schell, J. (1984): Restoration of virulence of vir region mutants of agrobacterium tumefaciens strain b6s 3 by coinfection with normal and mutant agrobacterium strains. - Molecular and General Genetics MGG 195(1-2): 159-163.

[86] Padmalatha, V, K.., Dhandapani, G., Kanakachari, M., Kumar, S., Dass, A., Patil, D. P., Rajamani, V., Kumar, K., Pathak, R., Rawat, B. (2012): Genome-wide transcriptomic analysis of cotton under drought stress reveal significant down-regulation of genes and 
pathways involved in fibre elongation and up-regulation of defense responsive genes. Plant Molecular Biology 78(3): 223-246.

[87] Persson, Ö., Valadi, Å., Nyström, T., Farewell, A. (2007): Metabolic control of the escherichia coli universal stress protein response through fructose $\square 6 \square$ phosphate. Molecular Microbiology 65(4): 968-978.

[88] Petropoulos, S., Daferera, D., Polissiou, M., Passam, H. (2008): The effect of water deficit stress on the growth, yield and composition of essential oils of parsley. - Scientia Horticulturae 115(4): 393-397.

[89] Posé, D., Castanedo, I., Borsani, O., Nieto, B., Rosado, A., Taconnat, L., Ferrer, A., Dolan, L., Valpuesta, V., Botella, M. A. (2009): Identification of the Arabidopsis dry $2 /$ sqe $1 \square 5$ mutant reveals a central role for sterols in drought tolerance and regulation of reactive oxygen species. - The Plant Journal 59(1): 63-76.

[90] Qin, X., Zeevaart, J. A. (1999): The 9-cis-epoxycarotenoid cleavage reaction is the key regulatory step of abscisic acid biosynthesis in water-stressed bean. - Proceedings of the National Academy of Sciences 96(26): 15354-15361.

[91] Quisenberry, J., McMichael, B. (1991): Genetic variation among cotton germplasm for water-use efficiency. - Environmental and Experimental Botany 31(4): 453-460.

[92] Quisenberry, J., Wendt, C., Berlin, J., McMichael, B. (1985): Potential for using leaf turgidity to select drought tolerance in cotton. - Crop Science 25(2): 294-299.

[93] Ribas, A. F., Pereira, L. F. P., Vieira, L. G. E. (2006): Genetic transformation of coffee. Brazilian Journal of Plant Physiology 18(1): 83-94.

[94] Saiki, R. K., Scharf, S., Faloona, F., Mullis, K. B., Horn, G. T., Erlich, H. A., Arnheim, N. (1985): Enzymatic amplification of b-globin genomic sequences and restriction site analysis for diagnosis of sickle cell anemia. - Science 230(4732): 1350-1354.

[95] Sairam, R., Tyagi, A. 2004. Physiological and molecular biology of salinity stress tolerance in deficient and cultivated genotypes of chickpea. - Plant Growth Regul 57(10).

[96] Shao, H.-B., Chu, L.-Y., Jaleel, C. A., Zhao, C.-X. (2008): Water-deficit stress-induced anatomical changes in higher plants. - Comptes Rendus Biologies 331(3): 215-225.

[97] Shinozaki, K., Yamaguchi-Shinozaki, K. (2007): Gene networks involved in drought stress response and tolerance. - Journal of Experimental Botany 58(2): 221-227.

[98] Showler, A. T. 2002. Effects of water deficit stress, shade, weed competition, and kaolin particle film on selected foliar free amino acid accumulations in cotton, Gossypium hirsutum (L.). - Journal of Chemical Ecology 28(3): 631-651.

[99] Singh, R., Pandey, N., Naskar, J., Shirke, P. A. (2015): Physiological performance and differential expression profiling of genes associated with drought tolerance in contrasting varieties of two gossypium species. - Protoplasma 252(2): 423-438.

[100] Sivamani, E., Bahieldin, A., Wraith, J. M., Al-Niemi, T., Dyer, W. E., Ho, T.-H. D., Qu, R. (2000): Improved biomass productivity and water use efficiency under water deficit conditions in transgenic wheat constitutively expressing the barley hval gene. - Plant Science 155(1): 1-9.

[101] Small, I., Wintz, H., Akashi, K., Mireau, H. (1998): Two birds with one stone: Genes that encode products targeted to two or more compartments. - Plant Molecular Biology 38(1): 265-277.

[102] Smith, E. F., Townsend, C. O. (1907): A plant-tumor of bacterial origin. - Science 25(643): 671-673.

[103] Somerville, C., Browse, J. (1991): Plant lipids: Metabolism, mutants, and membranes. Science 252(5002): 80-87.

[104] Sousa, M. C., McKay, D. B. (2001): Structure of the universal stress protein of haemophilus influenzae. - Structure 9(12): 1135-1141.

[105] Specht, J., Chase, K., Macrander, M., Graef, G., Chung, J., Markwell, J., Germann, M., Orf, J., Lark, K. (2001): Soybean response to water. - Crop Science 41(2): 493-509.

[106] Sturm, R. A. (2009): Molecular genetics of human pigmentation diversity. - Human Molecular Genetics 18(R1): R9-R17. 
[107] Tang, W., Page, M. (2013): Overexpression of the arabidopsis atem6 gene enhances salt tolerance in transgenic rice cell lines. - Plant Cell, Tissue and Organ Culture (PCTOC) 114(3): 339-350.

[108] Tanou, G., Filippou, P., Belghazi, M., Job, D., Diamantidis, G., Fotopoulos, V., Molassiotis, A. (2012): Oxidative and nitrosative $\square$ based signaling and associated post $\square$ translational modifications orchestrate the acclimation of citrus plants to salinity stress. - The Plant Journal 72(4): 585-599.

[109] Taylor, B. I.., Burbidge, A., Thompson, A. J. (2000): Control of abscisic acid synthesis. Journal of Experimental Botany 51(350): 1563-1574.

[110] Tinland, B. (1996): The integration of t-DNA into plant genomes. - Trends in Plant Science 1(6): 178-184.

[111] Turner, N. C. (1981): Techniques and experimental approaches for the measurement of plant water status. - Plant and Soil 58(1): 339-366.

[112] Tzfira, T., Li, J., Lacroix, B., Citovsky, V. (2004): Agrobacterium t-DNA integration: Molecules and models. - Trends in Genetics 20(8): 375-383.

[113] Umbeck, P., Johnson, G., Barton, K., Swain, W. (1987): Genetically transformed cotton (Gossypium hirsutum L.) plants. - Nature Biotechnology 5(3): 263-266.

[114] Ünyayar, S., Kelep, Y., Ünal, E. (2004): Proline and aba levels in two sunflower genotypes subjected to water stress. - Bulg. J. Plant Physiol. 30: 34-47.

[115] Urao, T., Miyata, S., Yamaguchi-Shinozaki, K., Shinozaki, K. (2000): Possible his to asp phosphorelay signaling in an arabidopsis two $\square$ component system. - Febs Letters 478(3): 227-232.

[116] Vereyken, I. J., Chupin, V., Demel, R. A., Smeekens, S. C., De Kruijff, B. (2001): Fructans insert between the headgroups of phospholipids. - Biochimica et Biophysica Acta (BBA)-Biomembranes 1510(1): 307-320.

[117] Vierling, E., Kimpel, J. A. (19920: Plant responses to environmental stress. - Current Opinion in Biotechnology 3(2): 164-170.

[118] Voloudakis, A. E., Kosmas, S. A., Tsakas, S., Eliopoulos, E., Loukas, M., Kosmidou, K. (2002): Expression of selected drought-related genes and physiological response of greek cotton varieties. - Functional Plant Biology 29(10): 1237-1245.

[119] Wang, W., Vinocur, B., Altman, A. (2003): Plant responses to drought, salinity and extreme temperatures: Towards genetic engineering for stress tolerance. - Planta 218(1): $1-14$.

[120] Wanner, L. A., Junttila, O. (1999): Cold-induced freezing tolerance in arabidopsis. Plant Physiology 120(2): 391-400.

[121] Wilkinson, J. Q., Lanahan, M. B., Conner, T. W., Klee, H. J. (1995): Identification of mrnas with enhanced expression in ripening strawberry fruit using polymerase chain reaction differential display. - Plant Molecular Biology 27(6): 1097-1108.

[122] Wu, Q.-S., Xia, R.-X., Zou, Y.-N. (2008): Improved soil structure and citrus growth after inoculation with three arbuscular mycorrhizal fungi under drought stress. - European Journal of Soil Biology 44(1): 122-128.

[123] Xu, S., Li, J., Zhang, X., Wei, H., Cui, L. (2006): Effects of heat acclimation pretreatment on changes of membrane lipid peroxidation, antioxidant metabolites, and ultrastructure of chloroplasts in two cool-season turfgrass species under heat stress. - Environmental and Experimental Botany 56(3): 274-285.

[124] Yadav, S., Lakshmi, N. J., Maheswari, M., Vanaja, M., Venkateswarlu, B. (2005): Influence of water deficit at vegetative, anthesis and grain filling stages on water relation and grain yield in sorghum. - Indian Journal of Plant Physiology 10(1): 20.

[125] Zaenen, I., Van Larebeke, N., Teuchy, H., Van, M. Montagu, Schell, J. (1974): Supercoiled circular DNA in crown-gall inducing agrobacterium strains. - Journal of Molecular Biology 86(1): 109IN19117-116127.

[126] Zahur, M., Maqbool, A., Irfan, M., Barozai, M. Y. K., Qaiser, U., Rashid, B., Husnain, T., Riazuddin, S. (2009): Functional analysis of cotton small heat shock protein promoter 
region in response to abiotic stresses in tobacco using agrobacterium-mediated transient assay. - Molecular Biology Reports 36(7): 1915-1921.

[127] Zambryski, P., Joos, H., Genetello, C., Leemans, J., Van Montagu, M., Schell, J. (1983): Ti plasmid vector for the introduction of DNA into plant cells without alteration of their normal regeneration capacity. - The EMBO Journal 2(12): 2143.

[128] Zhang, C.-S., Lu, Q., Verma, D. P. S. (1995): Removal of feedback inhibition of $\delta 1-$ pyrroline-5-carboxylate synthetase, a bifunctional enzyme catalyzing the first two steps of proline biosynthesis in plants. - Journal of Biological Chemistry 270(35): 20491-20496.

[129] Zhang, F., Puchta, H., Thomson, J. G. (2015): Advances in New Technology for Targeted Modification of Plant Genomes. - Springer, New York.

[130] Zhang, J., Campbell, R. E., Ting, A. Y., Tsien, R. Y. (2002): Creating new fluorescent probes for cell biology. - Nature Reviews Molecular Cell Biology 3(12): 906-918.

[131] Zhu, B., Su, J., Chang, M., Verma, D. P. S., Fan, Y.-L., Wu, R. (1998): Overexpression of a $\delta$ 1-pyrroline-5-carboxylate synthetase gene and analysis of tolerance to water-and salt-stress in transgenic rice. - Plant Science 139(1): 41-48.

[132] Zhu, T., Mettenburg, K., Peterson, D. J., Tagliani, L., Baszczynski, C. L. (2000): Engineering herbicide-resistant maize using chimeric rna/DNA oligonucleotides. Nature Biotechnology 18(5): 555-558. 